\title{
CARDIORESPIRATORY EFFECTS OF INTRAVENOUS $N$-METHYL-D-ASPARTATE CHALLENGE IN ANAESTHETIZED RATS
}

\author{
Katarzyna Kaczyñska and Matgorzata Szereda-Przestaszewska \\ Laboratory of Respiration Physiology, PAS Medical Research Centre, Warsaw, Poland
}

\begin{abstract}
SUMMARY
1. Experiments were performed to determine the effects of systemic application of $N$-methyl-D-aspartate (NMDA) on respiratory variables and blood pressure in 22 urethane/ chloralose-anaesthetized, spontaneously breathing rats.

2. Bolus injection of NMDA at a dose of $27 \mu \mathrm{mol} / \mathrm{kg}$, i.v., in neurally intact rats evoked a depression of breathing, most apparent at $30 \mathrm{~s}$, comprising a decrease in tidal volume $(P<0.001)$ and respiratory rate $(P<0.001)$. The expiratory apnoea appeared in three intact rats only.

3. The respiratory effects of NMDA were independent of the vagal integrity between lungs and the nodose ganglia. Elimination of supranodose connection to the medulla reduced the prolongation of the expiratory time $(P<0.01)$.

4. $N$-Methyl-D-aspartate induced an initial rise in blood pressure followed by hypotension in rats treated by infra- and supranodose vagotomy.

5. It is concluded that the respiratory response to systemic NMDA challenge occurs beyond lung vagi and indicates that neurons of the nodose ganglia contribute to NMDA inhibition of the expiratory time.

Key words: $N$-methyl-D-aspartate, nodose ganglia, pattern of breathing, systemic administration, vagus nerves.
\end{abstract}

\section{INTRODUCTION}

$N$-Methyl-D-aspartate (NMDA) receptors, a subclass of receptors for glutamate, the dominant mediator of excitatory transmission in the central nervous system, are extensively distributed in neurons of the brain. ${ }^{1} \mathrm{~N}$-Methyl-D-aspartate receptors are postulated to play a significant role in excitation of respiratory neuronal activity and to mediate the critical component of cardiorespiratory control in anaesthetized animals. Lengthening of inspiration observed after systematically applied NMDA receptor blockade in vagotomized cats $^{2}$ and rats ${ }^{3,4}$ implies the involvement of NMDA receptors in the control of inspiratory termination. It has been shown that central

Correspondence: Katarzyna Kaczyñska, Laboratory of Respiration Physiology, PAS Medical Research Centre, 5 Pawiñski St., 02-106 Warsaw, Poland. Email: kkacz@cmdik.pan.pl

Received 21 July 2003; revision 4 October 2003; accepted 18 October 2003.
NMDA receptors mediate carotid chemoreceptor responses, because their blockade with MK-801 significantly diminishes the response to hypoxia. ${ }^{5} \mathrm{~N}$-methyl-D-aspartate receptors have been shown to contribute to bradycardic and hypotensive responses evoked by L-glutamate microinjection into the NTS. Microinjection of a selective NMDA receptor blocker (2-amino-5phosphonovaleric acid (AP-5)) antagonized the cardiovascular effect of L-glutamate. ${ }^{6}$

Numerous studies that focused on the role of central NMDA receptors in the control of breathing, used the application of NMDA antagonists and quite seldom, if ever, agonists. Injection of NMDA into ventrolateral regions of the lateral parabrachial nucleus elicited tachypnoeic and hyperpnoeic responses in the cat. ${ }^{7}$ Activation of NMDA receptors at the ventrolateral nucleus tractus solitarius (NTS) by bilateral microinjection of NMDA produced an increase in expiratory duration and evoked apnoeas during the expiratory phase of the respiratory cycle in rats. ${ }^{8,9}$ In this species, NMDA receptors, localized in the NTS, have been shown to contribute partially to the ventilatory effects mediated by pulmonary $\mathrm{C}$ fibre afferent pathways. ${ }^{10}$

All visceral organs with parasympathetic innervation are endowed with NMDA receptors. ${ }^{11}$ In the peripheral nervous system, NMDA receptors have been found in autonomic and sensory ganglia (trigeminal, nodose, superior cervical, sphenopalatine ${ }^{12}$ ), in the laryngeal and tracheal neurons ${ }^{13}$ and on visceral vagal afferent terminals. ${ }^{14}$ The contribution of peripheral NMDA receptors to respiratory reflexes is far from being elucidated. To the best of our knowledge, there has been no study quantifying the cardiorespiratory effects of NMDA applied systemically. Yet, peripheral NMDA receptors existing outside the brain may have physiological and pharmacological importance as targets for drug actions.

In our experiments, we examined whether presumable excitation of receptors situated in the intrapulmonary airways, accessible through the pulmonary circulation, and those present on vagal nodose ganglia modify the respiratory pattern.

The present study started with the hypothesis that stimulation of peripheral NMDA receptors with NMDA will depress respiratory motor output by afferent pathways from the pulmonary vagal endings. This hypothesis has been tested by measuring the ventilatory effects of NMDA in neurally intact rats and after elimination of vagal afferent input below and above the nodose ganglia.

\section{METHODS}

Twenty-two adult Wistar rats (250-390 g bodyweight) were anaesthetized with an intraperitoneal (i.p.) injection of $600 \mathrm{mg} / \mathrm{kg}$ urethane (Sigma, 
Poznañ, Poland) and $120 \mathrm{mg} / \mathrm{kg} \alpha$-chloralose (Fluka AG, Poznañ, Poland). Additional doses of anaesthetic were administered intravenously (i.v.) to maintain a constant level of surgical anaesthesia. Animals were placed supine and breathed spontaneously with room air. The femoral artery and vein were catheterized to monitor blood pressure and for further injections, respectively. In some animals, the right atrium was cannulated through the catheter inserted via an external jugular vein. The trachea was exposed in the neck, sectioned below the larynx and the cannula inserted into the caudal end connected to a pneumotachograph. The midcervical segments of the vagi and the areas of nodose ganglia were cleared from adjacent tissue, dissected and prepared for section later in the experiment. A schematic illustration of the experimental procedure is shown in Fig. 1.

Prior approval for the experimental protocol used in the present study was obtained from the 1st Warsaw's Animal Experimentation Ethics Committee. All animal procedures were in accordance with the National Institutes of Health Guide for the Care and Use of Laboratory Animals (http://www.nih.gov).

Arterial blood pressure was measured with a pressure transducer (CK 01; Mera-Tronik, Warsaw, Poland) and blood pressure monitor (MCK 4011; Mera-Tronik) and mean arterial pressure (MAP) was calculated. Tidal volume $\left(\mathrm{V}_{\mathrm{T}}\right)$ signals were recorded from the pneumotachograph (Electrospirometer C56; Mercury, Glasgow, UK). End-tidal $\mathrm{CO}_{2}$ was measured with a capnograph (Engstrom Eliza Plus; Gambro, Bromma, Sweden). Electromyograms of the costal diaphragm were recorded with bipolar electrodes. Activity was amplified $(\times 1000-5000)$ with an NL104 amplifier (Digitimer, Welwyn Garden City, UK), band-pass filtered $(50 \mathrm{~Hz}-50 \mathrm{kHz})$ and measured with a model AS101 (Asbit, Warsaw, Poland) leaky integrator (time constant $=100 \mathrm{msec}$ ). Recordings were registered on an Omnilight 8M36 apparatus (Honeywell, Tokyo, Japan). Rectal temperature was maintained at $38^{\circ} \mathrm{C}$ with a heating pad.

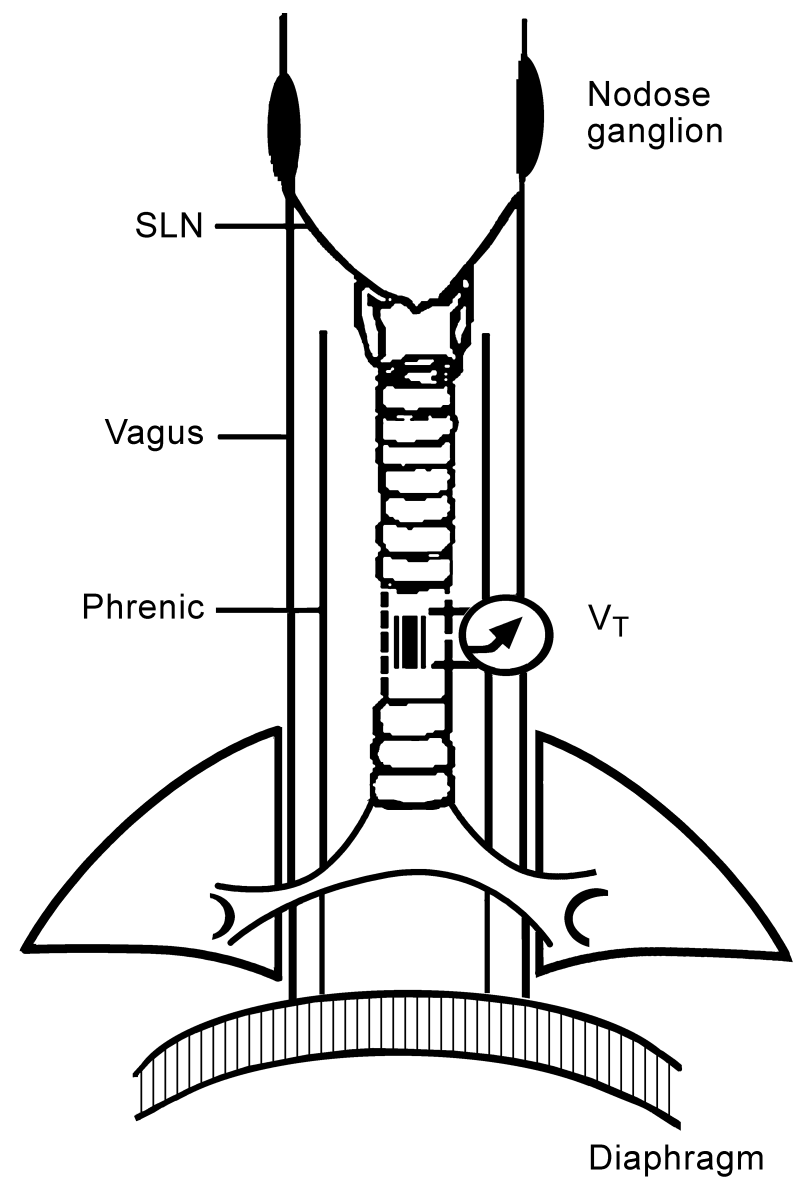

Fig. 1 A schematic drawing of the experimental procedure. SLN, superior laryngeal nerve; $\mathrm{V}_{\mathrm{T}}$, tidal volume.
$N$-Methyl-D-aspartate ([R]-2-[methylamino] succinic acid; Sigma), at a dose of $27 \mu \mathrm{mol} / \mathrm{kg}$ bolus, was delivered in $0.2 \mathrm{~mL}$ aliquots of physiological saline. The dose of NMDA used in these experiments was derived from establishing dose-response relationships shown in Fig. 2. All drug administrations were followed by a flush of $0.2 \mathrm{~mL}$ saline via a catheter placed in the right femoral vein or right atrium. Test i.v. or right atrium injections of $0.2 \mathrm{~mL}$ aliquots of physiological saline showed no volume effects.

The respiratory effects of NMDA challenge were recorded in 13 rats in the first series of experiments that were either neurally intact or following section of cervical vagi. In the second series of experiments, NMDA was injected in nine initially vagotomized rats prior to and after supranodose vagotomy. Each individual value of $\mathrm{V}_{\mathrm{T}}$, ventilation $\left(\mathrm{V}_{\mathrm{E}}\right)$ and respiratory rate (f) was taken as an average of five consecutive breaths. The ventilatory parameters were assessed prior to NMDA injection, during the early phase and at 30 and $60 \mathrm{~s}$ after challenge. The expiratory time $\left(\mathrm{T}_{\mathrm{E}}\right)$ was determined from the record of integrated diaphragm activity. Prolongation of $T_{E}$ was measured as the ratio of maximal $\mathrm{T}_{\mathrm{E}}$ at $30 \mathrm{~s}$ after NMDA challenge ( $\left.T_{E N M D A}\right)$ to the respective control $T_{E}$ value $\left(T_{E}\right.$ control $)$. Ventilatory responses were assessed by comparing the mean of five consecutive breaths during the period of breathing following NMDA injection to the mean of five preceding breaths $($ control $=$ prechallenge values) and are expressed as absolute changes.

The parameters $\mathrm{V}_{\mathrm{T}}, \mathrm{V}_{\mathrm{E}}$ and $\mathrm{f}$ were analysed by two-way ANOVA with time (prechallenge, early post-challenge, $30 \mathrm{~s}$ and $60 \mathrm{~s}$ after challenge) and innervation status (intact and vagi cut) as repeated measures factors. Prolongation of the expiratory time $\left(\mathrm{T}_{\mathrm{ENMDA}} / \mathrm{T}_{\mathrm{E} \text { control }}\right)$ was analysed by repeated-measures one-way ANOvA. Differences between individual time points and experimental situations were evaluated by contrast analysis. In all cases, $P<0.05$ was considered significant. Results shown are the mean \pm SEM.

\section{RESULTS}

The dose-response curves of Fig. 2 illustrate changes in the respiratory variables produced by a series of i.v. injections of

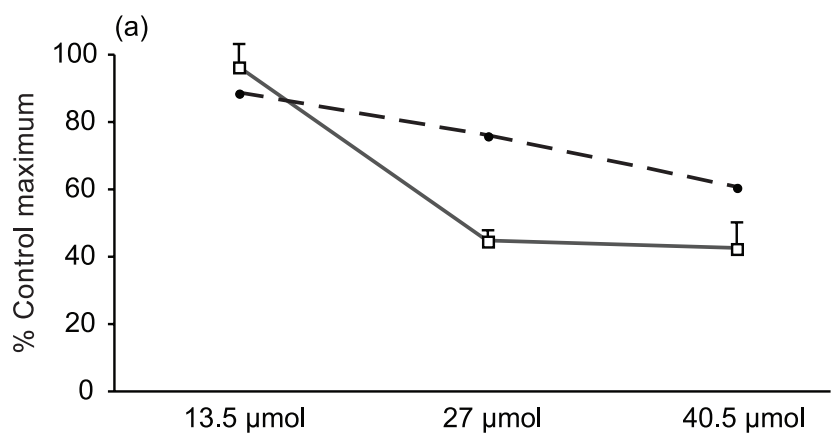

(b)

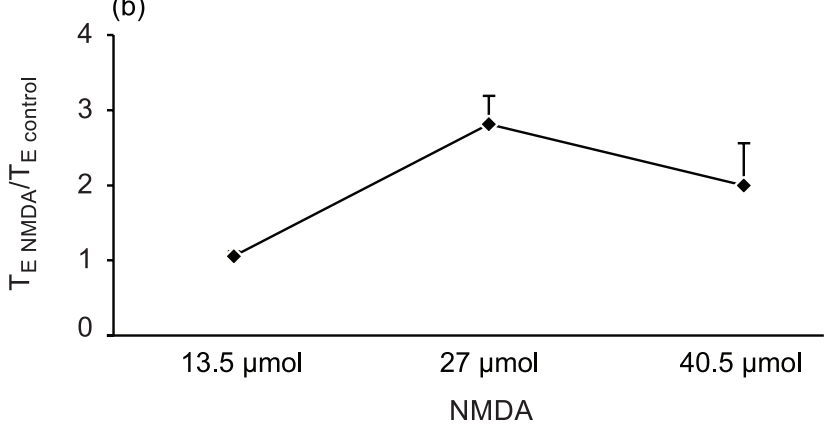

Fig. 2 Effects of various doses of intravenous injections of $N$-methyl-Daspartate (NMDA) on respiration. (a) Maximal change in tidal volume (-) and frequency of breathing ( $\square$ ), expressed as a percentage of control. (b) Relationship between the NMDA dose and mean prolongation of expiratory time $\left(\mathrm{T}_{\mathrm{E}}\right)$. Data are mean $\pm \mathrm{SEM}(n=5)$. 
NMDA, ranging from 13.5 to $40.5 \mu \mathrm{mol}$, in intact rats. The results clearly indicate that depressed ventilation with a vivid impact on expiratory inhibition results from a dose of $27 \mu \mathrm{mol}$ NMDA. This dose was applied in the following experiments.

Because no differences were found between cardiorespiratory responses to NMDA injected into the right atrium and the femoral vein, the results were pooled and treated as an intravenous challenge.

Intravenous injection of NMDA in all 10 rats of the first group induced depression of breathing, which affected both components of the respiratory pattern: a decrease in tidal volume and respiratory rate. Figure 3 illustrates a typical response to injection of NMDA into the femoral vein in the intact rat.

Two-way ANOVA revealed a significant effect of NMDA challenge $\left(F_{3,27}=19.55 ; P<0.00001\right)$ on tidal volume. The fall in $\mathrm{V}_{\mathrm{T}}$ started immediately after NMDA challenge and reached its lowest value at $30 \mathrm{~s}$ in intact and midcervically vagotomized rats, not being different from baseline at $60 \mathrm{~s}$ (Table 1).
Analysis of variance demonstrated a significant effect of NMDA challenge $\left(F_{3,27}=16.9 ; P<0.00001\right)$ on respiratory rate. The decrease in respiratory rate was not simultaneous with the initial fall in tidal volume and achieved its maximum at $30 \mathrm{~s}$. The decrease in respiratory rate lasted until $60 \mathrm{~s}$ after NMDA challenge in both neural states (Table 1).

Analysis of variance yielded a significant effect of NMDA challenge $\left(F_{3,27}=22 ; P<0.000001\right)$ on minute ventilation. Minute ventilation decreased immediately after NMDA injection, being most affected at $30 \mathrm{~s}$. The significant fall reached $54 \pm 10 \mathrm{~mL} / \mathrm{min}$ $(P<0.0001)$ in intact rats and $62 \pm 10 \mathrm{~mL} / \mathrm{min}(P<0.001)$ in vagotomized rats compared with baseline values of $101 \pm 11$ and $111 \pm 15 \mathrm{~mL} / \mathrm{min}$, respectively. The effect persisted for $60 \mathrm{~s}$ before and after midcervical vagotomy.

Figure $4 \mathrm{a}$ shows the mean prolongation of $\mathrm{T}_{\mathrm{E}}$ after NMDA administration, which was not significantly different $\left(F_{1,9}=0.05\right.$, $P=0.8$ ), between neurally intact rats and those with sectioned lung vagi.

Table 1 Changes in tidal volume and respiratory rate after intravenous $N$-methyl-D-aspartate challenge

\begin{tabular}{|c|c|c|c|c|c|c|c|c|c|}
\hline \multirow[b]{3}{*}{ Innervation status } & \multirow[b]{3}{*}{$n$} & \multicolumn{4}{|c|}{$\mathrm{V}_{\mathrm{T}}(\mathrm{mL})$} & \multicolumn{4}{|c|}{$\mathrm{f}(/ \mathrm{min})$} \\
\hline & & & & After NMDA & & & & After NMDA & \\
\hline & & Baseline & Early phase & $30 \mathrm{~s}$ & $60 s$ & & Early phase & $30 \mathrm{~s}$ & $60 \mathrm{~s}$ \\
\hline Intact & 10 & $1.77 \pm 0.20$ & $1.67 \pm 0.21 *$ & $1.47 \pm 0.20 * * *$ & $1.70 \pm 0.23$ & $56 \pm 2$ & $55 \pm 3$ & $35 \pm 3 * * *$ & $49 \pm 3 *$ \\
\hline Vagi cut & 10 & $2.04 \pm 0.24$ & $1.92 \pm 0.25^{* * *}$ & $1.62 \pm 0.25 * *$ & $1.92 \pm 0.24$ & $53 \pm 2$ & $53 \pm 2$ & $37 \pm 4 * *$ & $43 \pm 3^{*}$ \\
\hline Vagi cut & 9 & $2.59 \pm 0.09$ & $2.41 \pm 0.07 * *$ & $2.26 \pm 0.14 *$ & $2.46 \pm 0.18$ & $54 \pm 2$ & $55 \pm 2$ & $33 \pm 4 * * *$ & $49 \pm 2$ \\
\hline Nodose ganglia removed & 9 & $3.14 \pm 0.24$ & $3.01 \pm 0.27$ & $2.76 \pm 0.26^{*}$ & $3.02 \pm 0.27$ & $57 \pm 2$ & $56 \pm 2$ & $44 \pm 3^{* * \dagger}$ & $51 \pm 1 * *$ \\
\hline
\end{tabular}

All values are the mean \pm SEM. $* P<0.05, * * P<0.01, * * * P<0.001$ compared with the respective pre- $N$-methyl-D-aspartate (NMDA) value; ${ }^{\dagger} P<0.05$ compared with the corresponding pre-supranodose vagotomy value (two-way ANOVA followed by planned-contrast analysis).

$\mathrm{V}_{\mathrm{T}}$, tidal volume; $\mathrm{f}$, respiratory rate.
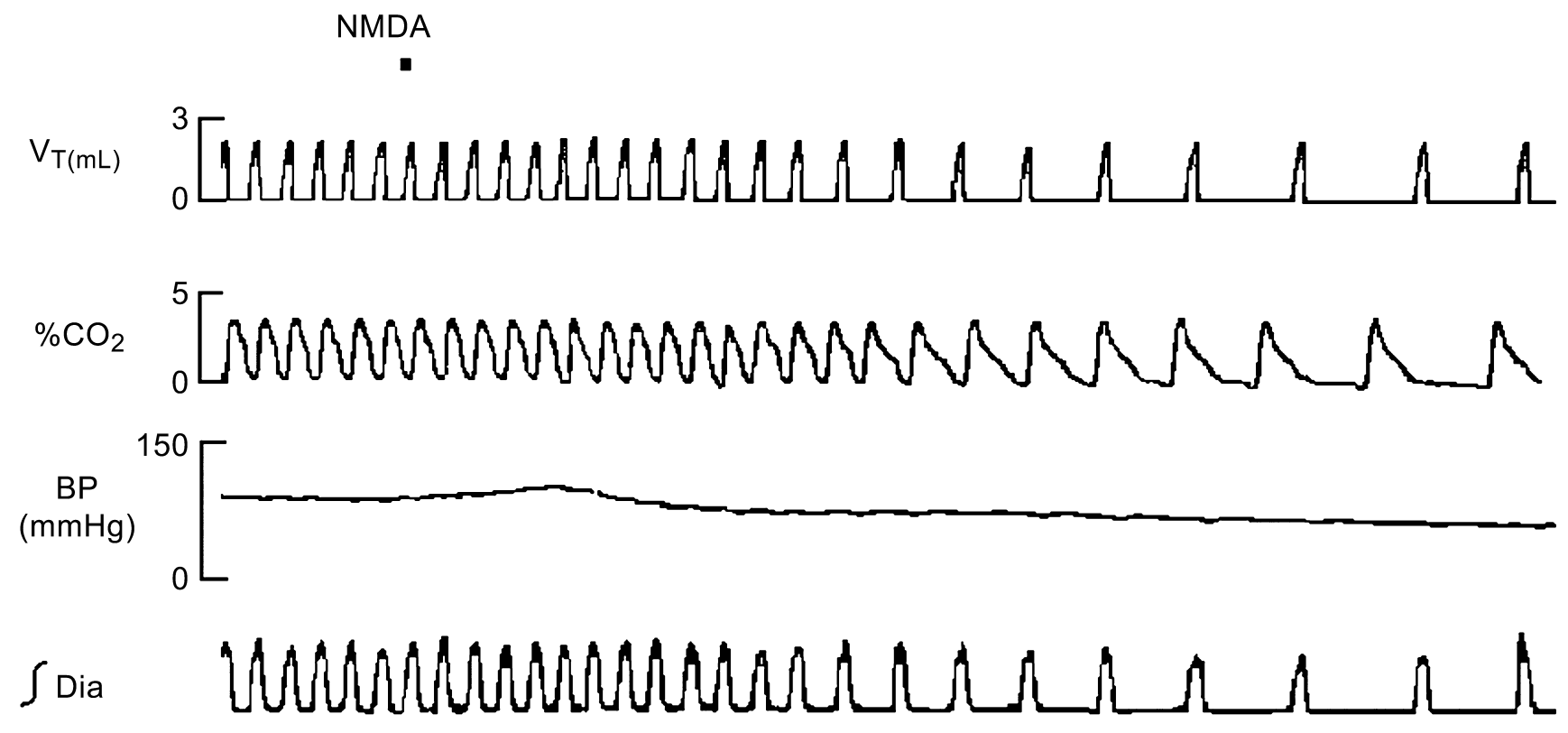

Fig. 3 Respiratory response to intravenous injection of $N$-methyl-D-aspartate (NMDA) in the intact rat. The time of injection of NMDA is marked with a dot above the upper trace. $N$-Methyl-D-aspartate administration induced prolonged inhibition of respiratory rate, which was associated with decreased tidal volume $\left(\mathrm{V}_{\mathrm{T}}\right) . \% \mathrm{CO}_{2}$, end-tidal $\mathrm{CO}_{2}$; $\mathrm{BP}$, systemic blood pressure; [Dia, integrated electromyogram of the diaphragm. 
$\mathrm{N}$-Methyl-D-aspartate-evoked depression of breathing was coupled with changes in MAP. At the early post-NMDA phase, MAP was increased in intact rats. At 30 and $60 \mathrm{~s}$ following NMDA challenge, MAP remained at a reduced level, near baseline values. In animals undergoing midcervical vagotomy, there was a biphasic change in arterial pressure, comprising a prompt rise and then, at $30-60 \mathrm{~s}$, a prolonged hypotension (Table 2).

Three of 13 intact rats responded in a different way to intravenous NMDA administration (they were excluded from statistical analyses). In these three rats, apart from bradypnoeic breathing, NMDA evoked delayed expiratory apnoea of a mean duration of $11.7 \pm 6.2 \mathrm{~s}$. Postapnoeic breathing showed a transient increase in tidal volume.

To determine whether nodose ganglia participate in mediating the response to intravenous NMDA injection, NMDA was administered to nine initially vagotomized rats prior to and after supranodose vagotomy.

Two-way ANOVA revealed a significant effect of NMDA challenge $\left(F_{3,24}=7.11 ; P<0.01\right)$ on tidal volume. The fall in tidal volume appeared at the early phase after NMDA challenge, remained decreased until $30 \mathrm{~s}$ and reverted to baseline values within $60 \mathrm{~s}$ in initially vagotomized rats. After supranodose vagotomy, post-NMDA tidal volume depression was confined to $30 \mathrm{~s}$ (Table 1).

Two-way ANOvA revealed a significant effect of NMDA challenge $\left(F_{3,24}=43.8 ; P<0.0001\right)$ and a significant effect of challenge-denervation status interaction $\left(F_{3,24}=3.9 ; P<0.05\right)$ on respiratory rate. The decline in respiratory rate after NMDA

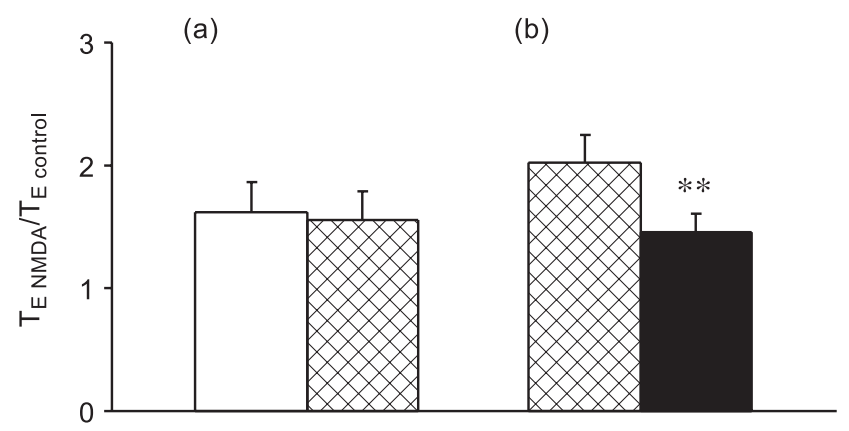

Fig. 4 Effect of mid-cervical vagotomy in intact rats $(\mathrm{a} ; n=10)$ and subsequent section of the supranodose vagi $(\mathrm{b} ; n=9)$ on $N$-methyl-D-aspartateinduced prolongation of expiratory time $\left(\mathrm{T}_{\mathrm{E}}\right)$. $* * P<0.01 \quad\left(F_{1,8}=13.8\right)$ compared with presupranodose neurotomy (one-way ANOVA). ( $\square$ ), intact rats; (ख), vagi cut; (ם), nodose ganglia removed. challenge was confined to $30 \mathrm{~s}$ in midcervically vagotomized rats. In rats that subsequently underwent supranodose vagotomy, the decrease in respiratory rate lasted until $60 \mathrm{~s}$. The response at $30 \mathrm{~s}$ was evidently reduced compared with the corresponding value in rats with a preserved supranodose connection (Table 1).

Minute ventilation was decreased in both neural states $\left(F_{3,24}=30.4 ; P<0.000001\right)$. The largest drop, observed at $30 \mathrm{~s}$ following NMDA injection, lowered the baseline from $141 \pm 9$ to $83 \pm 16 \mathrm{~mL} / \mathrm{min}(P<0.001)$ in midcervically vagotomized rats and from $182 \pm 18$ to $125 \pm 17 \mathrm{~mL} / \mathrm{min}(P<0.01)$ after supranodose vagotomy.

$\mathrm{N}$-Methyl-D-aspartate challenge caused a biphasic response of blood pressure in rats vagotomized at the midcervical and supranodose levels. The prompt rise in MAP at the early phase changed into hypotension at $30 \mathrm{~s}$ and reverted to near baseline values at $60 \mathrm{~s}$ (Table 2).

Supranodose vagotomy significantly diminished the prolongation of $\mathrm{T}_{\mathrm{E}}$, which was $2.02 \pm 0.23$ before and $1.46 \pm 0.16$ after denervation $(P<0.01$; Fig. $4 \mathrm{~b})$.

\section{DISCUSSION}

These experiments have demonstrated that NMDA injection into the femoral vein evokes a short-lived respiratory depression. The response consisted of depressed tidal volume and lowered respiratory rate. The occurrence of apnoea was not a constant phenomenon, being observed in three intact animals only. Earlier investigations on the respiratory effects of NMDA have not focused on the ventilatory effects of systemically administered NMDA. As mentioned in the Introduction, activation of NMDA receptors in the region of the NTS was described to elicit apnoea, ${ }^{8,9}$ accompanied by a decrease in MAP and heart rate, ${ }^{10}$ in rats. In contrast, NMDA injection into the brainstem chemoreceptor projections site induced an increase in minute ventilation. ${ }^{15}$

Excitatory amino acid receptors in peripheral tissue have been much less extensively studied. This is the first report describing the respiratory response to peripheral NMDA administration. In the present experiments, the depressive action of systemic NMDA on respiration led to a prolongation of $\mathrm{T}_{\mathrm{E}}$ and, in some animals, to delayed apnoeic spells. Similarly, NMDA microinjection to the NTS of rats showed prolongation of $\mathrm{T}_{\mathrm{E}} \cdot{ }^{9}$ In the present study, NMDA administered into the pulmonary circulation evoked a depression of the tidal and timing components of the breathing pattern. It may be suggested that depressed respiratory motor output results from stimulation of NMDA receptors situated within the reach of the pulmonary circulation.

Table 2 Changes in mean arterial pressure after intravenous $N$-methyl-D-aspartate challenge

\begin{tabular}{|c|c|c|c|c|c|}
\hline \multirow[b]{3}{*}{ Innervation status } & \multirow[b]{3}{*}{$n$} & \multicolumn{4}{|c|}{ MAP $(\mathrm{mmHg})$} \\
\hline & & & & After NMDA & \\
\hline & & Baseline & Early phase & $30 \mathrm{~s}$ & $60 \mathrm{~s}$ \\
\hline Intact & 10 & $87 \pm 5$ & $112 \pm 7 * * *$ & $81 \pm 9$ & $73 \pm 8$ \\
\hline Vagi cut & 10 & $86 \pm 8$ & $100 \pm 9 *$ & $67 \pm 8 *$ & $65 \pm 8^{*}$ \\
\hline Vagi cut & 9 & $89 \pm 5$ & $120 \pm 4 * * *$ & $72 \pm 7 *$ & $81 \pm 6$ \\
\hline Nodose ganglia removed & 9 & $84 \pm 6$ & $113 \pm 7 * * *$ & $61 \pm 3 * * *$ & $74 \pm 4$ \\
\hline
\end{tabular}

All values are the mean \pm SEM. $* P<0.05, * * * P<0.001$ compared with the respective pre- $N$-methyl-D-aspartate (NMDA) value (two-way ANOVA followed by planned-contrast analysis).

MAP, mean arterial pressure. 
The type of respiratory response does not argue for activation of the pulmonary $\mathrm{C}$ fibre afferent system, which is prone to produce a regular apnoea, followed by fast breathing. ${ }^{16}$ The prolongation of $\mathrm{T}_{\mathrm{E}}$ observed in the present study may be due to increased phasic activity of the pulmonary stretch receptors, which results in a decrease of tidal volume. ${ }^{17}$ This is only our presumption, because there are no experimental data available showing whether and how NMDA affects the activity of stretch receptors. $N$-Methyl-Daspartate receptors on the neurons of the NTS, mediating the Breuer-Hering reflex ${ }^{3}$ and responsible for the emergence of apnoea, ${ }^{18}$ are also present on lung vagal afferents. ${ }^{11}$ The relatively high concentration of exogenous NMDA following challenge to the pulmonary circulation should activate the receptors in the periphery in a similar manner. However, in our experiments, vagal feedback from the lungs was not essential for the decrease in tidal volume and slowing of respiratory rate. The lack of involvement of the vagi in the ventilatory response cannot entirely discount the possibility that the inhibitory effects of NMDA on the timing component may depend on activation of NMDA receptors in the nodose ganglia and supranodose vagi. These receptors were found expressed on parasympathetic ganglia, vagal afferents ascending from the parasympathetic ganglia and on the nodose ganglion. ${ }^{11,12}$ Then, it would seem reasonable to assume that the possible site of NMDA action in the periphery may be the nodose ganglia, which remained intact in first series of experiments. However, in the second series of experiments, supranodose vagotomy did not preclude the decrease in both tidal volume and frequency of breathing. Nevertheless, the effect of NMDA on the latter variable was diminished, which is expressed by a significantly lesser prolongation of $\mathrm{T}_{\mathrm{E}}$ after removal of the nodose ganglia.

However, it cannot be assumed that the drug is not affecting respiratory related neurons. The permeability of the blood-brain barrier to NMDA given systemically has not yet been quantified. The high potency of this compound after topical application to some medullary areas compared with less appreciable effects following peripheral administration suggests lower blood-brain penetrability. ${ }^{19}$ Thus, whether the effects of NMDA on respiration are the result of direct or indirect action on respiratory related neurons remains to be determined.

The blood pressure response triggered by NMDA was similar in all neural states: a short-lived rise was followed by a a decline. The depressor effect was significant after division of the vagi at both the midcervical and supranodose levels. The prompt hypertensive response may depend on the catecholamines secretion induced by NMDA. ${ }^{11}$ Several records in the paper by Bonham et al. ${ }^{9}$ show that microinjection of NMDA into the NTS in rats produced both an increase and fall in blood pressure. Intracerebroventricular NMDA injection in conscious rats elicited hypertension ${ }^{20}$ and the same effect was obtained after NMDA microdialysis of the locus coeruleus in anaesthetized rats. ${ }^{21}$ Thus, the type of blood pressure response appears to be associated with the site of drug application. The pressor and depressor effects observed in the present experiments may be attributed to stimulation of NMDA receptors in the brain, assuming that NMDA partially crosses the blood-brain barrier. Furthermore, activation of NMDA receptors present on the spinal neurons, ${ }^{22}$ sympathetic ganglia ${ }^{12}$ and even in the heart ${ }^{13}$ could, conceivably, contribute to the blood pressure changes. There is, however, another explanation. Excitation of NMDA receptors was suggested to initiate nitric oxide (NO) production. ${ }^{13}$ This may cause indirect changes in blood pressure evoked by stimulation of blood vessels with NO. It has been shown experimentally that NO released from activated neurons endowed with NMDA receptors induced dose-dependent pial arteriolar vasodilatation. ${ }^{23}$

In summary, we have shown that the overall respiratory response to injection of NMDA into the femoral vein or into the right atrium bears the traits of short-lived respiratory depression. The inhibition of central respiratory drive occurs beyond the lung vagi, which does not support our initial hypothesis. $N$-Methyl-D-aspartate receptors endowing nodose and supranodose afferentation appear to be responsible for the inhibitory effect on the timing component of the breathing pattern.

\section{ACKNOWLEDGEMENT}

We thank Mrs Teresa Warnawin for her excellent technical assistance.

\section{REFERENCES}

1. Yamazaki H, Haji A, Okazaki M, Takeda R. Immunoreactivity for glutamic acid decarboxylase and $N$-methyl-D-aspartate receptors of intracellularly labeled respiratory neurons in the cat. Neurosci. Lett. 2000; 293: 61-4.

2. Foutz AS, Champagnat J, Denavit-Saubié M. Involvement of $N$ methyl-D-aspartate (NMDA) receptors in respiratory rhythmogenesis. Brain Res. 1989; 500: 199-208.

3. Connelly CA, Otto-Smith R, Feldman JL. Blockade of NMDA receptor-channels by MK-801 alters breathing in adult rats. Brain Res. 1992; 596: 99-110.

4. Monteau R, Gauthier P, Rega P, Hilaire G. Effects of $N$-methyl-Daspartate (NMDA) antagonist MK-801 on breathing pattern in rats. Neurosci. Lett. 1990; 109: 134-9.

5. Gozal D, Xue YD, Simakajornboon N. Hypoxia induces c-Fos protein expression in NMDA but not AMPA glutamate receptor labeled neurons within the nucleus tractus solitarii of the conscious rat. Neurosci. Lett. 1999; 262: 93-6.

6. Canesin RO, Bonagamba LGH, Machado BH. Bradycardic and hypotensive responses to microinjection of L-glutamate into the lateral aspect of the commissural NTS are blocked by an NMDA receptor antagonist. Brain Res. 2000; 852: 68-75.

7. Takayama K, Miura M. Respiratory responses to microinjection of excitatory amino acid agonists in ventrolateral regions of the lateral parabrachial nucleus in the cat. Brain Res. 1993; 604: 217-23.

8. Berger I, Gillis RA, Vitagliano S et al. NMDA receptors are involved at the ventrolateral nucleus tractus solitarii for termination of inspiration. Eur. J. Pharmacol. 1995; 277: 195-208.

9. Bonham AC, Coles SK, McCrimmon DR. Pulmonary stretch receptor afferents activate excitatory amino acid receptors in the nucleus tractus solitarii in rats. J. Physiol. 1993; 464: 725-45.

10. Vardhan A, Kachroo A, Sapru HN. Excitatory amino acid receptors in the nucleus tractus solitarius mediate the responses to the stimulation of cardio-pulmonary vagal afferent C fiber endings. Brain Res. 1993; 618: $23-31$.

11. Erdö SL. Excitatory amino acid receptors in the mammalian periphery. Trends Pharmacol. Sci. 1991; 12: 426-9.

12. Shigemoto R, Ohishi H, Nakanishi S, Mizuno N. Expression of the mRNA for the rat NMDA receptor (NMDAR1) in the sensory and autonomic ganglion neurons. Neurosci. Lett. 1992; 144: 229-32.

13. Robertson BS, Satterfield BE, Said SI, Dey RD. N-Methyl-D-aspartate receptors are expressed by intrinsic neurons of rat larynx and esophagus. Neurosci. Lett. 1998; 244: 77-80.

14. Aicher SA, Sharma S, Pickel VM. N-Methyl-D-aspartate receptors are present in vagal afferents and their dendritic targets in the nucleus tractus solitarius. Neuroscience 1999; 91: 119-32. 
15. Vardhan A, Kachroo A, Sapru HN. Excitatory amino acid receptors in commissural nucleus of the NTS mediate carotid chemoreceptor responses. Am. J. Physiol. 1993; 264: R41-50.

16. Lee LY, Pisarri TE. Afferent properties and reflex functions of bronchopulmonary C-fibres. Respir. Physiol. 2001; 125: 47-65.

17. Schelegle E, Green JF. An overview of the anatomy and physiology of slowly adapting pulmonary stretch receptors. Respir. Physiol. 2001; 125: $17-31$.

18. Bonham AC, McCrimmon DR. Neurones in a discrete region of the nucleus tractus solitarius are required for the Breuer-Hering reflex in rat. J. Physiol. 1990; 427: 261-80.

19. France $\mathrm{CP}, \mathrm{Lu} \mathrm{Y}$, Woods $\mathrm{JH}$. Interaction between $\mathrm{N}$-methyl-Daspartate and CGS 19755 administered intramuscularly and intracerebroventricularly in pigeons. J. Pharmacol. Exp. Ther. 1990; 255: 1271-7.
20. Goren MZ, Onat F, Berkman K. Participation of NMDA and kainate receptors of paraventricular nucleus in cardiovascular responses to glutamate receptor agonist. Eur. J. Pharmacol. 2000; 388: 77-84.

21. Hall S, Milne B, Jhamandas K. Excitatory action of $N$-methyl-Daspartate on the rat locus coeruleus is mediated by nitric oxide: An in vivo voltammetric study. Brain Res. 1998; 796: 176-86.

22. Krenz NR, Weaver LC. Effect of spinal cord transection on $N$-methylD-aspartate receptors in the cord. J. Neurotrauma 1998; 15: 1027-36.

23. Domoki F, Perciaccante JV, Shimizu K, Puskar M, Busija DW, Bari F. N-Methyl-D-aspartate-induced vasodilation is mediated by endothelium-independent nitric oxide release in piglets. Am. J. Physiol. 2002; 282: H1404-9. 